\title{
Empirical Bibliography on Enterprise Resources Planning Systems Implementation
}

\author{
Yaw Marfo Missah \\ KNUST \\ Computer Science \\ Ghana-Kumasi
}

\begin{abstract}
The rapid development in technology has affected the business world today compelling organizations to respond to these changes in order to gain and sustain a competitive edge within the similarly increasing competitive business environment. Enterprise Resource Planning (ERP) is one of the technological tools that organizations are implementing in response to current increasingly competitive and demanding business world. Many business organizations are adopting ERP systems because of the strategic advantages associated with their adoption including, reduced costs, increased operational efficiency and effectiveness, automation, integrated business, and enhanced information flow. Therefore, the main goal of this research is help examine the challenges typical for the processes of ERP integration, use and maintenance. The research study and its findings are significant in terms of contemporary IT field, as it provides constructive evidence and facts regarding specific organization. Evidently, special and critical findings can be used in practice to prevent the negative effects from ERP integration at organizational and technological levels.
\end{abstract}

\section{General Terms}

Enterprise Resource Planning Systems, ERP Software

\section{Keywords}

Enterprise Resource Planning Systems, ERP Software, Implementation, Integration, Business processes

\section{INTRODUCTION}

In this paper, a critical analyzes of existing literature on the challenges encountered during implementation of ERP software is carried out. The paper is divided into three sections; background/history, theoretical framework and other research studies. The first part will provide a literature review describing the history and some benefits ERP, while the second part will provide an overview of the literature review on the theories of ERP implementation, the conceptual framework from which the study is based on. DeLone and McLean's Information System Success Model will be comprehensively discussed and its dimensions explained. The third part will comprehensively discuss challenges faced in implementation of ERP systems within organizations as defined in literature. The section will also provide a conclusion based on the reviewed literature concerning challenges of ERP implementation.

\section{A GENERAL OVERVIEW OF ERP SYSTEMS}

\subsection{Background/history}

Enterprise resource planning (ERP) system provides a guideline for integration and a common platform of how an organization is run, base on its business activities. The benefits of a successful ERP implementation include a better customer response, able to better control cost, data integrity and automated method which are well efficient [1].

In a brief history of ERP systems it has been indicated that ERP systems started in the 1960s around the same time as material requirements planning (MRP), which was collaboration between IBM and J.I. Case in an effort to have a better way of scheduling materials [2]. ERP evolved/progressed from manufacturing management systems (which have in the past three decades developed a simple process of calculating requirements for material and advanced evolved to make automation of an entire enterprise possible) [3]. The most recent generation of ERP systems is superior as it is more advanced and therefore more effective in tackling multiple business units including manufacturing, accounting, purchasing, customer relationship management, order processing, human resource management, operations planning and sales [3]. MRP II was found to have many problems. For example, the frequent changes that were experienced in forecasting sales required continual readjustments the processes used in production [3].The parameters set by the system were also found to be unsuitable under the changed conditions. This saw MRP II evolve to a generic ERP system as it is known today [1]. Organizations requiring short implementation cycles also highlighted the project management issues in the ERP implementation. ERP therefore stemmed from the extension and expansion of MRP II. Today, the goal of ERP is to tackle all the basic processes of an organization; irrespective of its business line.

In the 1990s the growth of ERP systems resulted in the demand for consulting services to prepare organizations for the changes that comes along with the implementation of an ERP system [4]. Successful implementation of ERP system is important to organizations as ERPs are believed to be a tactical tool in improving the organization normal way of doing business. Changes come as a result of improvements. Change management is surely a concern when organizations plan to implement ERP systems [5]. Besides changes in infrastructure, process changes and their related changes are inevitable. Related changes may include roles and responsibilities which may affect the power distance [6]. In addition, management and users required to acquire new knowledge is embedded in the new ERP systems [7]. ERP adoption and implementation is a complex and dynamic process with high uncertainty accompanied by unexpected problems [8]. Change management is a human-related matter which involves stakeholders of the ERP implementation [9]. Adoption of ERP systems are often accompanied by changes in organizational structure, culture and in how things (tasks by employees) are done [10]. That is, it generally changes the way the business is run within the firm. These changes affect the larger organization to a large extend and could result in 
resistance by the staff if not well managed. According to ERPs are large and complex information systems and their adoption introduces complex change which must be effectively managed for successful implementation [11]. Change management is the main challenge to ERP implementation [11]. Other important processes for ERP implementation include training [12]. Also, the effect of the ERP system use is also an important factor [13].

\subsection{Benefits of ERP systems}

Numerous benefits have been attributed to ERP systems. A well implemented ERP systems offer several strategic advantages for the adopting firm [14]. ERP systems enable integration of business processes as well as transactionsoriented data in the organization. They can also be applied in integration of inter-organizational supply chains, increases efficiency, eliminates use of manual and repetitive processes particularly in entering data hence minimizes errors that often result from re-entering of data in a different system, and significantly reduces the number of stand-alone systems as well as their associated costs while simultaneously reducing total lead or cycle times [15].

Also, ERP systems increase availability and accessibility to operational data, in doing so; they enhance information quality with regards to availability, reliability and relevance [4]. Furthermore, successfully implemented systems mirror best business enabling the adopting form to obtain expertise that is hard-wired in the software for its use [16]. A study demonstrated that ERPs facilitate enhanced visibility in addition to control of information and considerably improve quality of information for decision making [17]. These benefits can be grouped into four categories discussed below [18].

\subsubsection{Information accessibility and richness}

ERP systems enable organizations to generate new and improved information that is more accurate. They also make information that was previously inaccessible more available to various organizational departments and units. This leads to better control as well as governance of the organization. It also results in faster response times and improved planning as well as coordination of processes and activities [19]. Most important it enhances the decision making process allowing managers to make quality and more informed decisions [19].

\subsubsection{Process automation and integration}

Effective implementation of ERPs changes the business processes of a firm and streamlines them in accordance with built-in best practices of the ERP software. This enables standardization and leads to administrative savings by eliminating procedures that are manual and repetitive [20]. They also save on operational costs through business processes that are more efficient and aligned.

\subsubsection{IS systems modification and maintenance}

ERP software exists in the form of an integrated IT system rather than different loosely-coupled subsystems and individual business applications. This leads to reduction in IS costs hence enabling the organization to achieve economies of scale as well as scope [17]. ERP systems streamline processes as well as common IT tasks as they allow self-service functionality [17]. This eliminates the need for employing more people to serve others while at the same time reducing on the equipment and technology requirements for running individual processes [17]

\subsubsection{Organizational competence, efficiency and effectiveness}

Adoption of ERP systems results in organizational learning, business agility, customer satisfaction, employee empowerment and service quality which enhance growth as well as competitive edge of the firm. Strategic competence management is critical for innovative organizations and very important in maintenance of strategic advantage. Increasing competition due to globalization requires organizations to be highly competent for them to succeed [21]. Many practitioners are now using information systems including ERPs to increase efficiency [21]. ERP vendors offer special products which enhance competence planning as well as management and which integrate basic functions and business processes. Ifinedo and Nahar [21] point out that the main goal of ERP is integration and as such, it ensures that there is transparency within an organization and that all the relevant units and departments have enough access to information. Access to information makes it possible for managers to make strategic decisions as data extraction is effortless [21]. Various departments have the required information to perform their functions hence increasing the overall efficiency and effectiveness of the organization.

\subsection{Enterprise Software Implementation Stages}

Apart from making a choice on whom to do what, Enterprise Software implementation has to go through five complex stages: Structured Planning, Process Assessment, Data Compilation and Cleanup, Education and Testing, and Usage and Evaluation [22]. These stages add to the observation that ERP system implementation is a tedious and expensive process. The stages are:

\section{- $\quad$ Structured Planning}

This is the first and the most important stage in the process of Enterprise Software implementation. The stage involves the selection of a skillful project team, analysis of the current business processes, scrutiny of the internal and external organizational information and data flow, setting of vital objectives, and the formulation of a comprehensive implementation strategy.

\section{- Process Assessment}

- This is the second stage in implementing Enterprise Software, and it involves;

- Examining the prospective software features and capabilities

- Recognizing manual business procedures,

- Constructing standard working processes

- Data Compilation and Cleanup

This stage involves keying out data that is to be converted and the new data that would be required. Besides, the stage calls for the analysis of the compiled information for accuracy and completeness, and the unwanted or worthless data is discarded.

\section{- $\quad$ Education and Testing}

This stage helps in proofing the Enterprise Software and training users on the system's usage. This is the level at which the database is tested completely and certified by the selected project team. For conformity, the system is examined using various testing methods and procedures. An organization has to go beyond the challenges involved with organizing a broad 
internal orientation exercise where every relevant user is familiarized with the working of the new Enterprise Software.

\section{- Usage and Evaluation}

This is the last but continuing stage for the Enterprise Software implementation. The newly implemented system is deployed live within all the branches of an organization and is checked on a regular basis by the project team for any fault.If the Enterprise Software is projected and implemented successfully, then it is definitely going to serve an organization in improving its productivity [23]. However, there are several challenges encountered in the process of projecting, implementing as well as integrating Enterprise Software [23].

\subsection{Major vendors}

Developers and commercial distributors serve as the main providers of the ERP systems and, therefore, the quality of their products become an object of in-depth examination. The consideration of major vendors is formally important for understanding the competitive advantages of the actual ERP systems, as well as for viewing the ERP market in detail

\subsubsection{SAP}

The German company SAP began as an ERP company, and today it is a leading player in the ERP market. SAP's product lines include SAP ECC, SAP Business One, SAP Business by Design, SAP Business All-in-one. SAP's main focus is in manufacturing, distribution, services and financial, their industry expertise include the Aerospace and Defense, Automotive, Banking, Financial Service Provider, Healthcare, Consumer Products, Engineering, Higher Education etc (www. SAP.com)

\subsubsection{Oracle}

Oracle was originally known for its database systems developed in the early 20th century rather than ERP systems. The company expanded its share in the ERP market through organic growth and a number of high-profile acquisitions such as JD Edwards, PeopleSoft, Siebel, and CRM and so on. Given this particular growth model, Oracle has become a configurable and flexible option and excels in a best-of-breed environment. Oracle provides integrated business software and hardware systems. Oracle's ERP software solution offering includes products such as Oracle Fusion Applications, Oracle E-Business Suite, PeopleSoft Enterprise, Siebel, JD Edwards Enterprise One and JD Edwards World, Hyperion Financial Performance Management, Primavera Enterprise Project Portfolio Management. Surprisingly Oracle's focus is in the manufacturing, distribution, services and financial, with their industry expertise almost the same as SAP's (www.Oracle.com).

\subsection{Theories of ERP Implementation}

ERP implementation is a complex process that involves various forces working against each other [24]. It is obvious that, implementing an ERP system will mean replacing or changing the legacy systems. In other words large portions of the system could be replaced [24].

\subsubsection{Technology acceptance model (TAM)}

This model was develop from the Theory of Reasoned Action (TRA) which argues that attitude towards a certain behavior is influenced by behavioral beliefs concerning the consequences of engaging in the behavior [25]. TAM predicts that user acceptance is influenced by perceived usefulness as well as perceived ease of use. According to the model, user perceptions of system usefulness as well as perceived use of ease determine the user's attitude toward using the technology. Consequently, behavioral intentions determine actual use of the system. Different authors however have conflicting arguments with regard to this.

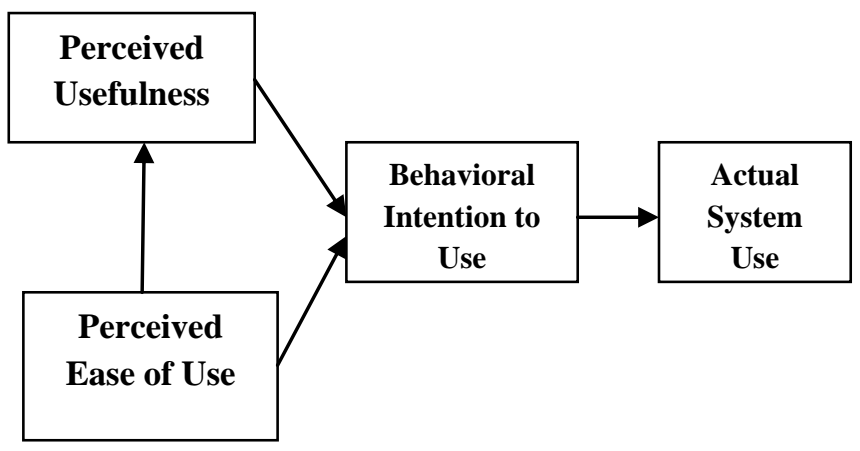

Figure 1. TAM Model. Reprinted from: Wikipedia, by Davis et.al (1989), Venkatech et.al (2003), Retrieved from http://istheory.byu.edu/wiki/Delone_and_McLean_IS_succ ess_model. Reprinted with permission.

\subsubsection{Perceived Ease of Use}

Perceived ease of use was subsumed in Task-Technology Fit in the ERP success model [26]. Perceived ease of use determines the perception of what a person thinks the ease of use of a particular system would be. Ramayah and other research indicated that perceived ease of use was a useful forecaster of perceived usefulness [27]. Related studies found respondents did not really care about ease of use as a good indicator in their selection of a system [39].

\subsubsection{Perceived Usefulness}

When a person is using a particular system, there is a degree to which the person might determine whether the system is enhancing his or her job; called perceived usefulness [29]. Information system acceptance will depend on perceived usefulness, since it can be seen as a measure to build on and will influence the successful implementation of a $n$ ERP system ( [30]; [26] ) It is worth noting that perceived usefulness affected behavioral intentions-to-use ERP system [31], an indication of computer systems use influence.

\subsubsection{Variance theory}

Variance theory has been widely used to explain how logical antecedents affect outcomes or rather, the relationship between the two. In this theory, the precursor (cause) is hypothesized as being a necessary as well as sufficient condition for the outcome [32]. In a variance theory that posits use of information technology as a cause of organizational efficiency, efficiency is always expected to take place whenever information is deployed [32]. Variance theory typically includes independent variables which are causally linked to the dependent variables. Causal links between variables are examined using the amount of variation in dependent variables that can be explained by a set of independent variables. The amount of explained variation is evaluated with measures of statistical association [33].

In the ERP related research, the application of variance theory can be divided into two main streams: critical success factors and the impacts resulting from ERP implementation. Most of the critical success factors of ERP implementation are well documented and analyzed. The impacts resulting from ERP implementation depend on each implementation experience hence there is no definite outcome [24]. There is no general consensus in academic and practitioners what the ERP 
implementation success is. The success of enterprise system was a multidimensional and relative concept [34]. A look at another framework for success in information systems [34], this framework has four phases (project chartering, the project, shakedown and onward and upward) for the enterprise system experience cycle and is based on the emergent process theory design [35]. Each phase has its own success metrics. The success factors of a particular phase will be the inputs of the next phase.

However, the success metrics for each phase cannot be generally applied to other enterprise system implementations. Each enterprise system experience was unique [34]. Different organizations will set different goals. The metrics for each phase will be different because the metrics are set against the goals. Moreover, randomness and external conditions may affect outcomes significantly. The "success" defined by Markus and Tanis [34] meant different things depending on who defined it [36]). [34] Also realized that the optimal success was a theoretical abstraction and might not be measurable or achievable practically [34]. System use was regarded as a measure of success in information system studies [37]. However, some authors ([38]; [39]) argued that system use was inappropriate for measuring ERP systems success because the use of ERP system was involuntary. Although DeLone and McLean [37] thought that no system use was totally mandatory, [31] indicated the mandatory usage for ERP system represented a base level needed to perform minimal job functions. Users could complete their daily operations by using the ERP system. They also pointed out that it was appropriate to examine behavioral intentionsto-use the system when the system use was mandatory. In the revised DeLone and
McLean [37] model, "intentions-to-use" was added as an alternative measure for the difficulties in interpreting the multidimensional aspects of "use". DeLone and McLean indicated that "intentions-to-use" was an attitude and "use" was behavior [37]. The substitution might resolve the process versus causal concerns and the mandatory versus voluntary issue. In the current study, based on the above review, intentions-to-use was the dependent variable which acted as the surrogate of the success of the implementation.

\subsubsection{DeLone and McLean's IS success model}

With the rapidly increasing investment in ERP systems worldwide, the associated high costs and the high probability of failure, many organizations and researchers find it essential to measure ERP systems success in order to determine its adoption. The Delone and Mclean Information System Success Model is widely accepted in information systems research as a standard or criterion for specifying as well as justifying the measurement of IS success as a dependent variable in these studies [40].

According to the model, IS researchers must be able to set apart management control variables from the desired with regard to use satisfaction, impacts and quality. The model [37] identifies six dimensions to information systems success as shown in the figure below. It argues that success of an IS can be symbolized by system quality, information quality (quality of the output), use (consumption) of the output, user's response to the IS and its output (user satisfaction), organizational impact (effect of the information system on the organization), and the effect of the information system on performance of the organization (organizational performance). Below is a diagrammatic representation of the model.

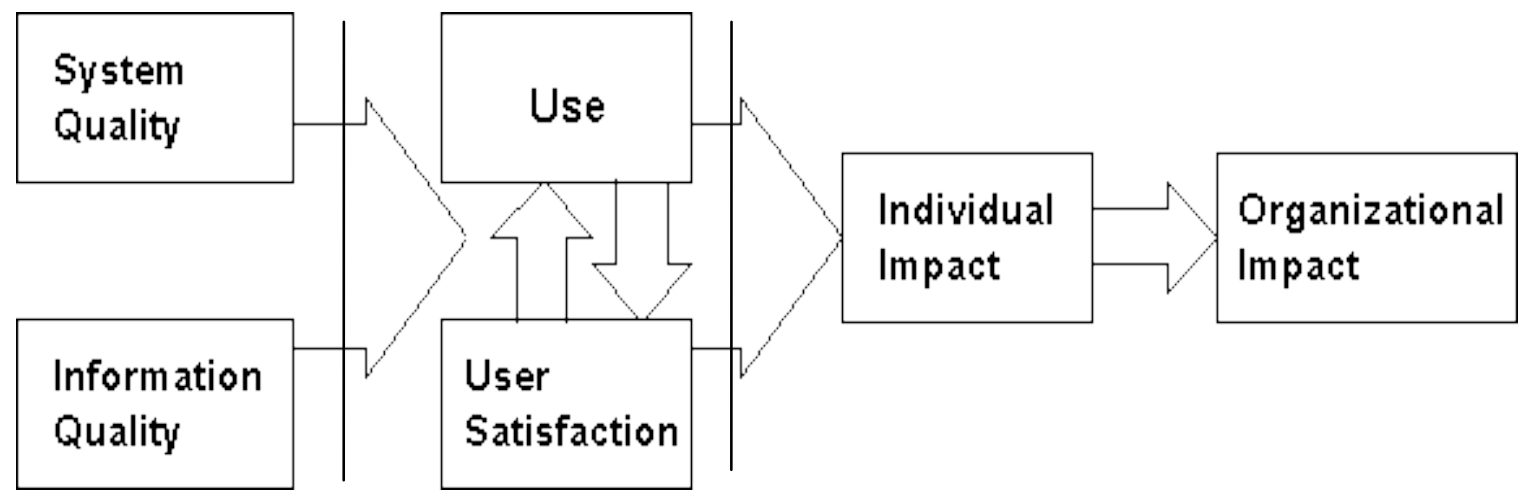

Figure 2 DeLone and McLean's IS Success Model. Reprinted from: Wikipedia, by W. H. DeLone and E. R McLean, 1992, Retrieved from http://istheory.byu.edu/wiki/Delone_and_McLean_IS_success_model. Reprinted with permission.

Mclean's model suggested that there are causal and temporal interdependencies among the six dimensions hence provided a strategy for categorizing the numerous information systems success measures. The authors of the model [37] provided a number of conclusions. First, they explain that since IS success is a multidimensional and interdependent variable, careful attention must be given to the definition as well as measurement of each its aspects. Specifically, measurement of the possible interactions amongst the success dimensions is required so as to isolate the effects of the different independent variable with either one or more of the discussed dependent success dimensions [40].

Secondly, the authors also proposed that while selection of success dimensions as well as measurements should be done based on objectives and based on empirical research, when and where possible, measures that should be used or selected should be those that have been tested and proven [40]. Third, in spite of the multidimensional as well as contingent features of IS success, efforts should be made to significantly reduce the number of different measures for measuring IS success. The measure should also be consistent to enable other researchers to compare their results and validate their research findings [40]. Fourth, it is essential to conduct more fieldstudy research which ought to investigate and incorporate measures for organizational impact [40]. Fifth and lastly, the success model requires further development as well as validation for it to be used in selection of suitable IS measures [40]. After acknowledging that the original model required further expansion and validation, an updated model is shown below [37] 


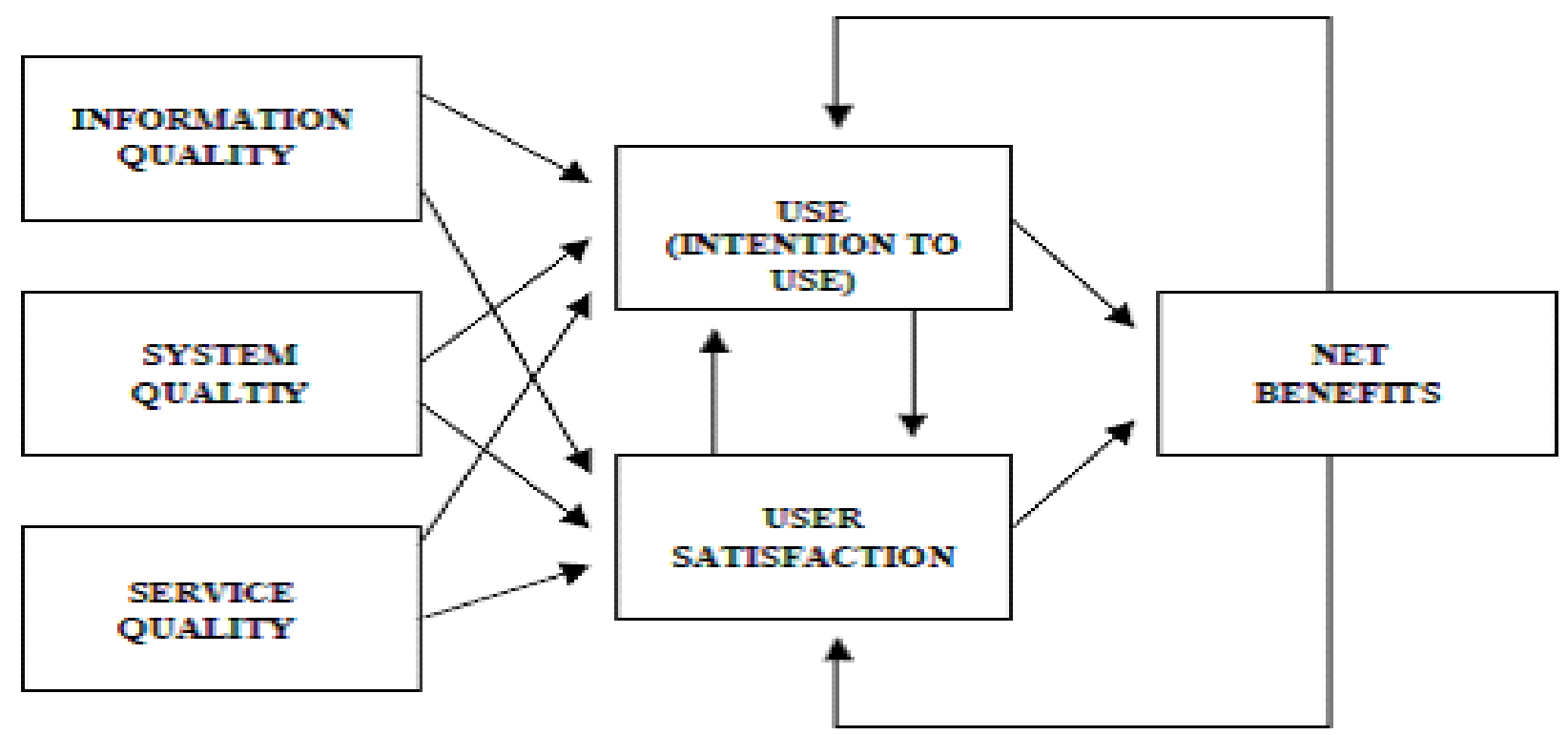

Figure 3 Revised DeLone and McLean's IS Success model. Reprinted from: Wikipedia, by Wei et.al. 2009, Retrieved from http://istheory.byu.edu/wiki/Delone_and_McLean_IS_success_model. Reprinted with permission.

The main differences between the original and the revised models are;

- The service quality variable was added to stress on the significance of service and support in successfully implemented e-commerce systems.

- The revised model added a measure for user attitude (user intention to use the IS).

- Flops in organizational and individual impact of the IS resulted in a final performance construct that was more ungenerous.

The revised taxonomy consisted of the following categories;

- $\quad$ System quality

- Information

- $\quad$ Service quality

- $\quad$ system use (intention to use)

- User satisfaction

- Net benefits (organizational and individual)

\subsubsection{System quality}

System quality concentrates on and is more concerned with the ERP's characteristics [40], productivity, ease of use, reliability and portability as some of characteristics of an ERP, that are related with system quality. Some refer to system quality construct as the ease of use to assess or measure the quality of the IS system in question [41].

Several studies have used this construct to signify success for various information systems including ERPs. Other researchers have examined the processing system itself to establish the contribution of IS to the organization. In addition to ease of use, other instruments that have been used to measure system quality include user friendliness, system throughput, ability to access authorization and locate data, and, quality of data in terms of currency, accuracy, level of detail and consistency.
A model developed by Wixom and Todd user satisfaction and technology use defined flexibility, accessibility, reliability, timeliness and integration as the dimensions for measuring system quality [41]. Another study described system quality in terms of response in time, ease of use and reliability [42]. The works of these two separated constructs are user-related and context-related from prior information system success models. They treated system quality as a concept that denotes IS success. A separate study identified nine validated/confirmed items that should be used to measure system quality for ERP success [43]. These are; ease of use and learning, system features, system accuracy, user requirements, flexibility, customization, sophistication and integration

\subsubsection{Information quality}

Information quality has been used in several studies to measure information systems success factors in ERPs. Information quality differs from system quality which focuses on the features of the information (mainly in form of reports) produced by the system. Information quality on the other hand is measured to establish whether the report (produced information) is concise, pertinent, usable, available, in the correct format and comprehensible. Information quality can be defined as measurement of outputs of an IS. They define accuracy, currency, completeness and format as the four antecedents of information quality [41].

Other researchers have investigated this dimension by measuring the usefulness or utility of the information acquired using an IS. Other developed measurements for information quality include; relevance, aggregation, uniqueness, clarity, readability, conciseness, decision relevance, sufficiency, freedom from bias, comparability and reliability [41]. Sedera and Gable have also identified three classes of information constructs [43];

- Informativeness which comprises of relevance, recentness, credibility, comprehensiveness and accuracy. 
- Accessibility which comprises of convenience, interpretability and timeliness.

\section{- Adaptability}

\subsubsection{Service quality}

It has been observed that most of the commonly used measures of information systems effectiveness focus more on the products and ignore the services of information system function. IS service quality is therefore very crucial in measuring the effectiveness of an IS. Researchers who have suggested that service quality be incorporated in the success model have applied the SERVQUAL (service quality) measurement model from marketing to an information system context [43]. SERQUAL model uses five dimensions of measurements; tangibles, assurance, reliability, empathy and responsiveness. Examples of instrument items are;

- $\quad$ ERP system is dependable (measure of reliability)

- $\quad$ ERP system hardware and software are up- to-date (tangible)

- $\quad$ ERP system employees give timely services to users (measurement of responsiveness)

- $\quad$ ERP system considers the interests of the users and has their best interest at heart (measurement of empathy)

- ERP system employees have the required knowledge to perform their tasks well (measurement of assurance).

Other studies have found that it is difficult to define and interpret the real meaning of service quality [7]. Research implies that service quality dimensions vary in relation to the context. Developing a universal measure for service quality is difficult. Service quality can be defined in electronic commerce context as the total support provided by the service provider, this applies in spite of whether this support is provided by a new organizational entity, the information system department or is outsourced from a service provide [37] as cited in [37]. The importance of the IS should be greater than it previously was as users are the firm's customers and therefore poor user support will result in loss of customers and sales. User training has therefore been included as a construct for measuring service quality particularly on a web portal. Others include; usefulness of content, accessibility to information, its adequacy, usefulness as well as interaction.

Service quality from a vendor/consultant point of view, the two can be regarded as external sources of expertise to the firm with regard to adoption and implementation of ERP [40]. These authors emphasize that the role of vendors and consultants is very crucial to the success of ERP implementation. Another study identified trustworthy, responsiveness, experience, assurance and reliability as constructs that determine service quality [44].

\subsubsection{System use}

System use refers to measurement of the extent to which an information system is used by individual users [7]. Some of the measures used for system use include; usage pattern, time of use, frequency of use, dependency (utilization), and number of accesses [42].

\subsubsection{User satisfaction}

User satisfaction refers to measurement of the response of the recipients to the use of the output (could be a report or information) of an IS [42]. User satisfaction is a continuous measurement of net benefits that come from using an IS [7]. One of the most essential desired outcomes of adopting an information system is to enjoy some benefits that are not possible with the current ways of doing things [40]. Therefore, for organizations to feel that an information system such as an ERP is successful, some benefits are some of the least expected outcomes. These benefits can include; efficiency in operations, reduced costs, enhanced flow of information, improved coordination of business processes, reduced inventory, improved customer service, reduced cycle times, increased customer service, standardized processes, improved quality and so forth. These benefits will enable the organization to improve their business operational capacity as well as achieving their business goals [45]

\subsubsection{Individual impact}

Individual impact refers to the measurement of the effect of information on the recipient's behavior. It is a difficult measure to define in a manner that is not ambiguous. Individual impact is closely associated with performance and therefore, statements such as "improving my division's performance" is definitely evidence that the IS has had a positive effect (impact). Individual impact is the perceived usefulness of an IS success on individual as well as organizational impact. They define individual impact as the extent to which an individual believes using the information system enhances their productivity as well as job performance [42]. In IS success study on ES [46], individual impact is defined as a measurement for their ES success measurement model [43]. They used four items in their model including; decision effectiveness, learning, individual productivity and awareness.

\subsubsection{Organizational impact}

This is a construct that seeks to measure the effect the information produced using an IS has on organizational performance. Measurement of system quality of an enterprise system must focus on the extent to which data is integrated with functionality [45]. They [45] added the following four measures; customization increased capacity, business process change and e-government. In another research, [43] identified eight items to use in measuring organizational impact; organizational costs, cost reduction, improved outputs, staff requirements, business process change, overall productivity, e-government, and increased capacity.

\section{ERP Studies}

\subsection{Challenges In ERP Software Implementation}

Several studies have been conducted to establish the source of challenges faced in ERP software implementation. Choice of software is one of the most crucial challenges faced in ERP implementation [47]. According to these authors, process integration is cited as the primary goal of implementation of most information technologies such as ERP. These authors define business process as a business process in which the effort that is associated with flow of information between various activities is reduced and business process integration as the process of reducing or minimizing this effort. They note that this effort is most effectively reduced by minimizing human effort that is associated with coordination and communication of their inputs as well as outputs. The degree 
of integration of a process is determined by the time information takes to flow between different activities. Integration process depends on the number of steps, handoffs and effort required with each hand off. The fewer the steps, as well as hand offs, and the lesser the effort, the better the integration of the process. The authors identify four principles that underlie organizational and information integration as;

\section{- Accessibility \\ - Timeliness \\ - Transparency \\ - Granularity}

However, they argue that the process of integration is difficult and reality makes it more complicated [48]. They argue that the new enterprise software such as ERP seek to successfully integrate business processes in organizations that were previously relied on function-based model for their operations, a goal which is very challenging to achieve. They further explain that that ERP software works by forming interconnection among different business processes as well as information flows to ensure that all units within an organization can access data from one point. Data that was initially handled departmentally has to be integrated and made available to all other departments within the organization.

According to these authors, integration existing stand-alone systems is a key challenge for most firms. This challenge is exacerbated by the reality that ERP software also aims at integrating business processes that were previously functionbased. For that reason, the process-orientation arising from the integration process is different from the operational differentiation which is emerging among conventional organizations. This study is however limited just to the integration aspect and does not take into account other variables such as project management, type of software and design , skill mix, employee involvement, training, organizational fit, technology planning and several others. ERP implementation can however only be successful if it is integrated and because of the many challenges that characterize the integration process, it can be argue that this article is useful. Several other studies have been conducted to establish the risk factors in implementation of ERP software. Studies on risk factors in information system projects have identified issues of software systems design, user involvement as well s training, project management, technology planning, social commitment, organizational fit, skill mix, and management structure as well as strategy.

\subsection{Organizational fit}

Factors related to organizational environment such as task complexity, resource insufficiency, magnitude of potential loss and extents of changes constitute major challenges in ERP implementation within firms [49]. Conflicts between people and user departments, poor specifications, lack of resources, changing scope are all organizational factors that the project manger has no control over yet they have adverse effect on implementation of an ERP system. Components of organizational fit as a challenge include failure of the organization to re- design its business processes, lack of data standardization as well as data integration, and not selecting an ERP software design which supports data integration [50]. It is up to the adopting firm to ensure that the ERP software they select fits with the organizational processes and functions.

\subsection{Skill mix}

A study conducted revealed that lack of the required expertise and skills including insufficient training as well as re-skilling, inadequate internal expertise, lack of ability to select, recruit and retain competent and qualified ERP system developers, ineffectively mixing of internal and external expertise and lack of or insufficient business analysts with the required business and technology knowledge [51]. It has also been explained that lack of user skills and experience, insufficient application-specific knowledge and lack of development know-how within the organization contribute to ERP implementation risk and should be addressed before attempts are made to undertake the project [50].

\subsection{Software systems and design}

Implementation risks related to scope and requirements/specifications include failure to understand the requirements and manage change effectively. An ineffective methodology as well as poor estimation can result in cost and or time overruns [52]. Some of the software risk factors include performance shortfalls, developing the wrong functions as well as user interface, continuously changing requirements by the user, deficiency in eternally supplied components and gold-plating [53]. Summaries this challenge has been summarized as failure to; comply with standardized specifications supported by the software, to efficiently integrate "add on" modules and, to recognize the significance of application-specific know-how [54].

\subsection{Management structure and security}

Challenges associated with management structure and strategies are several. One is lack of top management support and involvement [55], this is a very significant factor as no project can be successfully completed without the support of the senior management. It is emphasizde that when a project has no support from the top management, it is likely to stall because of inadequate or lack of the required resources and lack of leadership [7]. It is worth to note that approval must be sought from the top management in an organization for resources such as financial, materials and equipment to be allocated to a particular project, without the blessing of the top management, implementation of an ERP software is likely to fail particularly because of the huge amounts of financial resources involved in its implementation [7].

Top management commitment and involvement is also important in managing change particular user resistance. The top management is often used when new technologies are introduced to provide morale to employees and act as role models. They encourage use of the new technology by using it themselves. Leadership is therefore very crucial in implementation of ERP software as lack a champion would result in failure in achieving the intended goals of the system. Poor communication also results to disagreement on goals and objectives which is risky to successful implementation

Another factor is ineffective communication of system goals and objectives within the organization. Ineffective communication would result to failure as the ERP software might be installed but not used for the purpose it is intended for hence not realizing its goals. Effective information is crucial in ERP implementation in obtaining approval for implementation, creating an understanding within the organization and facilitating sharing of information and reporting of feedback with regards to progress. It also helps in making the employees understand the reasons for implementing the system which helps in gaining acceptance. 
ERP adoption leads to a major organizational change in terms of organizational structure, the people in the organization and business processes [56]. These changes are a source of benefits as well as costs, both tangible and intangible. Change management is therefore essential for the firm to realize financial returns on the huge investment as well as a competitive advantage. Lack of or an ineffective change management strategy is another factor that presents a serious challenge to successful ERP implementation [57]. Adoption of an ERP system within an organization implies introduction of new technology which changes the way things are done within the organization particularly in operations. This inevitably introduces change which management must find a way to manage.

Several research projects have illustrated that, employees always are resistant to change particularly one that affects how they work. ERP implementation results in changes in processes, infrastructure, in roles and responsibilities and sometimes in organizational structure and its management should be of priority to the adopting organization [58]. Since some ERP systems come from countries with a culture that is different from that of the adopting country, its implementation might involve introduction of aspects of a foreign culture which must be managed for success to be achieved [59].

Adoption of an ERP system also requires management as well as the users to acquire new knowledge on how to use the new ERP systems [60]. Humans generally do not like being forced to learn new things or make extra efforts particularly when it about something that they perceive to be complex such as new technology [61]. This could result in resistance. Employees might also resist the new technology for fear of losing their jobs as one of the benefits associated with ERP systems is automation. It has been described that, ERP implementation as a complex process that is also dynamic and characterized by high uncertainty as well as unexpected problems [8]. Change management is a matter that involves human resources within the organization and is very critical to successful implementation of ERP systems.

\subsection{User involvement and training}

User training is very important in ERP implementation as it is one of the major aspects of change management. Kumar et al. explained that for an ERP system to be effective, users must know how to use and apply it [62]. These authors emphasize that users must understand how the ERP system changes their way of working with regards to new procedures and processes, collaborative relationships, and integration with the ERP system. Many authors consider user training an important feature of ERP implementation. Its purpose is to make the users comfortable with the new system as well as to increase the knowledge and expertise level of employees [63]. The training program should cover features of an ERP system; ERP related models and concepts, as well as hands on training [64].

It is also found that involving users in the implementation process contributed to success [46]. They note that when users are not involved in the implementation process, they develop a negative attitude towards it and will likely resist using it. It is worth noting that insufficient training and re-training of end users, lack of commitment of users (clients) to project activities, ineffective communication and not being sensitive to user resistance are some of the factors that risk successful implementation of an ERP project [50].

\subsection{Technology planning}

ERPs are complex systems and require appropriate and sufficient technical expertise for successful implementation. Lack of adequate expertise and technology infrastructure to support the ERP system are among the main factors that contribute to failure and termination of IS projects [65]. The existing infrastructure must be compatible with the intended ERP technology and is capable of supporting it [66]. According to these authors, before investing in an ERP software project, it is essential to conduct a network assessment to establish the capacity of the existing infrastructure to back the new ERP system. They add that the existing infrastructure must also be compatible with the ERP system the company seeks to implement. Otherwise, the project will fail. An example of an ERP system project that failed because of inadequate existing infrastructure is the Hershey Foods ERP system. The technology being adopted must be linked to the corporate strategy [67]. Application complexity, technological newness, size of the application and failure of the application or technology to meet user specifications are some of the risk factors associated with challenges of technology planning [50].

\subsection{Project management}

Ineffective project management is a serious challenge to ERP implementation and can actually jeopardize the whole process [68]. According to these authors, failure to re-engineer project management within an organization that intends to adopt an IS system is one sure way of failing. Project management entails application of skills as well as knowledge in organizing and coordinating scheduling and monitoring process to ensure that the defined objectives are accomplished.

An effective implementation plan identifies and defines project tasks/activities, commits personnel as well as other resources such as financial, equipment and material to the defined activities and enhances organizational support by coordinating the implementation process [69]. The following project management practices are very critical to successful ERP implementation [70];

- Scope management

- Communication management

- $\quad$ Risk management

- Procure management

- Human resources management

- Integration management

Tambovcevs and Merkuryev agree and add that analysis of systems characteristics and risk factors is very crucial to successful implementation of an IS [46]. They suggest the following as some of the aspects of good project management which enhance successful ERP software implementation; good communication, competent project manager, strong leadership, staff training, balanced project team, commitment by users to change, understanding the firm's culture, its needs and the guidelines/procedures for successful ERP software implementation and complete changes in business and operation processes so that they are aligned with the new IS [71].

Similarly, scope creep, poor risk as well as vendor management, and inadequate allocation of financial and human resources over time are some of the most common 
problems associated with poor project management and which risk successful implementation of an ERP software [72]. It is worth to note that most technology related projects fail because of time and cost overruns as well as failure to meet specifications. These are the three main dimensions of project management. Project management is in fact the most crucial challenge to successful ERP implementation as most problems arise out of weaknesses in various aspects of project management [73].

\subsection{Social commitment}

Implementing an ERP projects are also largely affected by distinctive organizational as well as human practices, traditions, patterns regarding belief and action, and value project- related factors [74]. Most organizations tend to overlook problems of IT projects and their impact might remain unknown for a considerable period of time. When projects encounter problems however, the problems tend to escalate because of societal norms such as need to save face which compels the organization to continuing investing resources in a project that is failing. This may increase risk. To minimize problems during implementation, it is essential to put in place effective feedback systems and use them in identifying problems so that they can be redefined and addressed. This may include considering other alternatives to achieving the project goals and preparing the stakeholders for this crucial decision. Projects' whether it is information technology related or not are more likely to fail when the users have unrealistic expectations. Such users will be unsatisfied with the project outcomes and are likely to reject it [44].

\subsection{Cultural aspects}

National culture also has a great impact on ERP software implementation [75]. A study conducted revealed that cultural differences can be a major challenge particularly in adoption of an IS that seeks to enhance innovation such as ERP systems [76]. They found that the effect was negative in countries that have higher levels of masculinity, power distance and uncertainty avoidance. According Ge and Voss [75], these cultural differences worsen when comparisons are made between western countries such as the US and Eastern countries such as India. In their examination of the applicability of ERP systems that are Western designed to China, they found that these systems are founded on "rule based" established and mature economies rather than the Chinese "relation based" governance systems.

Other studies have compared adoption of locally developed systems to those that are foreign and in terms of impact on user satisfaction. The results reveal significantly higher user satisfaction for local systems as they consider the preferences of the local user [75]. A good example of difference in preferences between the West and the East is that while ERP system reports tend to be online in the west, workers in Asia prefer reports that are paper based. The implication is that while ERP is a global product and has similar benefits when effectively implemented, the software designed for a particular market might not be applicable to another that is culturally different. Organizations must therefore select ERP software that is suitable to the local culture to avoid cases of employee resistance.

\subsection{Integration challenges}

Enterprise Software and ERP implementation is continually a tough task for any organization. To be successful in implementing Enterprise Software and ERP systems, business need to be extremely heedful. This consultant advises that when SMEs think of Enterprise Software and ERP implementation, they ought to key out their need of that system. They accordingly need to come up with a preimplementation strategy for Enterprise Software and ERP software. This strategy, calls for the documentation of business demands, fiscal provisioning for the procurement of Enterprise Software and ERP system and services, and assessment of various Enterprise Software and ERP systems to suit a specific business process. After nailing down the enterprise system, businesses start to implement and eventually adopt the Enterprise Software and ERP system across all its departments. Though it sounds easy and direct, the process of enterprise software implementation is environed by diverse challenges.

Observation that integration is regularly quoted as a primary goal linked to the implementation of Enterprise Software [77]. Enterprise Software forms interconnections amongst various business processes and information flows to make sure that all divisions in an establishment can get data in one of its units [48]. Data that was previously handled by distinct departments has to be integrated and availed to the organization as a whole. Jobs have to be redefined, novel procedures created, and business processes securely integrated across the company. There are concerned that the entire process of integration is challenging whereas the personnel are often not ready for new processes and roles [78].Many scholars including [59] have argued that integration of current stand-alone Enterprise Software is a key challenge for most organizations. This challenge is further perplexed by the reality that Enterprise Software also attempt to integrate business processes in companies which were formerly function-based. Accordingly, the process-orientation occasioning from the integration process is contrary to the operational differentiation which is popular among conventional organizations. While some Enterprise Software solutions resolve some technical challenges, there are more challenges in integrating various sorts of information and procedures applied by operational areas. Besides, there is a challenge involving data sharing, which may negate current business practices and philosophy [79]. It is also proven that the presence of integration challenges by saying that the challenge of integrating Enterprise Software is as old as ERP itself. Organizations are struggling to enhance the level of integration of their Enterprise Software with other apps i.e. ecommerce sites and legacy systems.

\section{CONCLUSION}

While implementation of ERP systems is associated with several benefits that are strategic to an organization particularly in enhancing its competitiveness through reduced costs, increased efficiency and effectiveness, enhanced process integration, improved quality as well as customer satisfaction and, efficiency in flow of information within the organization, its implementation is not easy but is characterized by several challenges that could result to enormous losses for the adopting organization if not well addressed. This is because the losses associated with failed ERP implementation are just as great as or more than the benefits associated with successful implementation.

An ERP system can only be beneficial to a company if it is founded on a strong foundation that can handle the increased load of the new applications being introduced. This is in terms of skills and competence of people who run the system, the processes in place and the infrastructure to carry the ES. An organization should also assess the amount of organizational change required for the adoption of the proposed ES. The 
employees should be trained accordingly to prevent resistance to the rapid change involved in adopting an ES and organizational structure changed to align it with the new systems. Most important, the proposed ES should fit well with the existing infrastructure. A misfit will result to failure as the existing server may not be able to handle the increased load that results from adopting the new complex system. Project management and planning are also critical for such projects which involve a lot in terms of investments and their complex nature. The challenges ERP software implementation are common and include; project management, management structure and strategy (which include; lack of top management support and commitment, change management, effective communication, and disagreements on goal setting), software systems and design (type of software), technology integration, social commitment, skill mix, employee training and involvement and technology planning.

\section{REFERENCES}

[1] Liisa Von, H., Sue, N., and Jenine, B. (2004). Qualitative implementation of enterprise wide systems.

[2] Robert, J., and Ted Weston Jr, F.C. (2007). Enterprise resource planning (ERP) - A brief history. Journal of Operations Management, 25(2), 357-363.

[3] Ngai, E.W., and Wat, F.K. 2008. Examining the critical success factors in the adoption of enterprise resource planning. Computer Industry, 10. 1-17.

[4] Armbrüster, T., and Kipping, M. (2003). Strategy consulting at the crossroads: Technical change and shifting market conditions for top-level advice. International Studies of Management and Organization, $32(4), 19-42$

[5] Kemp, M. J., and Low, G. C. (2008). ERP innovation implementation model incorporating change management. Business Process Management Journal, $14(2), 228-242$

[6] Esteves, J. M., and Bohorquez, V. (2007). An updated ERP systems annotated bibliography: 2001-2005. Communications of the Association for Information Systems, 19, 386-446.

[7] Lee, D. H., Lee, S. M., Olson, D. L., and Chung. S. W. (2010). The effect of organizational support on ERP implementation. Industrial Management + Data Systems, $110(2), 269-283$

[8] Kenett, R. S., and Raphaeli, O. (2008). Multivariate methods in enterprise system implementation, risk management and change management. International Journal of Risk Assessment and Management, 9(3), 258276

[9] Skok, W. and Legge, M. (2002), Evaluating enterprise resource planning (ERP) systems using an interpretive approach. Knowledge and Process Management., 9: 7282.

[10] Upadhyay, P., Basu, R., Adhikary, R., and Pranab, D. K. (2010). A comparative study of issues affecting ERP implementation in large scale and small medium scale enterprises in India: A Pareto Approach. International Journal of Computer Applications, 8(3), 23-28.

[11] Esteves, J., and Pastor, J., (2001). Analysis of critical success factors relevance along SAP implementation phases. Proceedings of the 7th Americas Conference on
Information Systems (AMCIS), Boston, Massachusetts, USA, 2001

[12] Rebecca L. Bechtel, Janice K. Squires, (2001) "Tools and techniques to facilitate change", Industrial and Commercial Training, 33(7), 249-255

[13] Kraemmerand, P., Moller, C., and Moller, H., (2003). ERP implementation: an integrated process of radical change and continuous learning. Production Planning and Control, 6(1).

[14] Shin I. (2006). Adoption of enterprise system software and firm performance. Small Business Economics, 26(3), 241-256.

[15] Cotteleer, M., and Bendoly, E. (2006). Order lead-time improvement following enterprise-IT implementation: an empirical study. MIS Quarterly, 30 (3): 643-660.

[16] Bendoly, E., Rosenzweig, E., and Stratman, J. (2009). The efficient use of enterprise information for strategic advantage: A data envelopment analysis. Journal of Operations Management, 27(4), 310.

[17] Seethamraju, R. (2008). Enterprise system's characteristics in small and medium-sized enterprises context - A case study. European and Mediterranean Conference on Information Systems.

[18] Gupta, M., and Kohli, A. (2006). Enterprise resource planning systems and its implications for operations function. Technovation, 26(5-6), 687-696.

[19] Kanet, J., and Stösslein, M. (2010). Integrating production planning and control: towards a simple model for Capacitated ERP. Production planning and control, 21(3), 286-300

[20] Forslund, H. (2010). ERP systems' capabilities for supply chain performance management. Industrial Management + Data Systems, 110(3), 351-367.

[21] Ifinedo, P., and Nahar, H. (2006). Impact and success of ERP systems: A study involving some firms in the Nordic-Baltic Region. Journal of Information Technology Impact, 6(1), 19-46.

[22] Berente, N., Vandenbosch, B., and Aubert, B. (2009). Information flows and business process integration. Business Process Management Journal, 15(1), 119-141.

[23] Hawari, A., and Heeks, R. (2008). Explaining ERP failure in a developing country: A Jordanian case study. Journal of Enterprise Information Management, 23(2), 135-160.

[24] Robey, D., Ross, J.W., and Boudreau, M. (2002) "Learning to implement enterprise systems: An exploratory study of the dialectics of change," Journal of Management Information Systems 19(1), 17-46.

[25] Morris, M., and Dillon, A. (1997) How User Perceptions Influence Software Use. IEEE Software, 14(4), 58-65.

[26] Smyth, M., L. (2001). Threats to ERP Success: A Case Study In: Proceedings of the $5^{\text {th }}$ Pacific-Asian Conference on Information Systems.

[27] Ramayah, T., Siron, R., Dahlan, N., \& Mohammad, O. (2002). Technology usage among owner/managers of the SMEs: The role of demographic and motivational variables. The proceedings of The 6th Annual Asian- 
Pacific Forum for Small Business on Small and Medium Linkages, Networking and Clustering.

[28] Kumar, V., Maheshwari, B., and Kumar, U. (2008). An investigation of critical management issues in ERP implementation: Empirical evidence from Canadian organizations. Technovation, 23(2003), 793-807.

[29] Davis, F. D.; Bagozzi, R. P.; Warshaw, P. R. (1989), "User acceptance of computer technology: A comparison of two theoretical models", Management Science 35, 982-1003

[30] Zviran, M., Pliskin N, and Levin R. (2005) "Measuring User Satisfaction and Perceived Usefulness in the ERP Context", Journal of Computer Information Systems. 65(3), 43-52.

[31] Amoako-Gyampah., K , A. F. Salam, An extension of the technology acceptance model in an ERP implementation environment, Information and Management, v.41 n.6, p.731-745, July 2004

[32] Markus, L., and Robey, D. (1988). Information technology and organizational change: Causal structure in theory and research. Management Science, 34(5), 583598.

[33] Sabherwal, R., and Robey, D. Reconciling Variance and Process Strategies for Studying Information Systems Development. Information Systems Research (6:4), 1995, pp. 303-323

[34] Markus, T. M., Axline, S., Petrie, D., and Tanis, C. (2002). Learning from adopters' experiences with ERP: Problems encountered and success achieved. Journal of Information Technology, 15(4), 245-265.

[35] Soh, Christina and Markus, M. Lynne, "How IT Creates Business Value: A Process Theory Synthesis" (1995). ICIS 1995 Proceedings. Paper 4

[36] Esteves, J., and Pastor, J., (2001). Analysis of critical success factors relevance along SAP implementation phases. Proceedings of the 7th Americas Conference on Information Systems (AMCIS).

[37] DeLone, W. H., and McLean, E.R. (2003). The DeLone and McLean model of information systems success: A ten year update, Journal of Management Information Systems, 19 (4), 9-30.

[38] Wu J-H and Wang Y-M (2006) Measuring KMS success: a respecification of the DeLone and McLean model. Information \& Management 43(6), 728-739

[39] Bernroider, E.W.N. (2008), "IT governance for enterprise resource planning supported by the DeLone-McLean model of information systems success", Information \& Management. 45(5), 257-69

[40] Wei, K. S., Loong, C. A., Leong, Y., \& Ooi, K. (2009). Measuring ERP system success: A respecification of the Delone and Mclean's IS Success Model. Symposium on Progress in Information and Communication Technology. 7-12

[41] Wixom, B. H., and Todd, P. A. (2006). A theoretical integration of user satisfaction and technology acceptance. Information Systems Research, 16(1): 85102
[42] Sabherwal, R., Jeyaraj, A., and Chowa, C. (2006). Information system success: individual and organizational determinants. Management Science, 52(12), 1849-1864.

[43] Sedera, D., and Gable, G. G. (2007). A factor and structural equation analysis of the enterprise systems success measurement model. Proceedings of the 25th International Conference on Information Systems.

[44] Wang, E.T.G., and Chen, J.H.F. (2006). Effects of internal support and consultant quality on the consulting process and ERP system quality. Decision Support System, 42(2), 1029-41

[45] Botta-Genoulaz, V.R., and Millet, P.-A. (2006). An investigation into the use of ERP systems in the service sector. International Journal of Production Economics, 99 (1-2): 202-21.

[46] Gable, G. G., Sedera, D., and Chan, T. (2008). Reconceptualizing information system success: the ISimpact measurement model. Journal of the Association for Information Systems, 9 (7), 377-408.

[47] Berente, N., Vandenbosch, B., and Aubert, B. (2009). Information flows and business process integration. Business Process Management Journal, 15(1), 119-141

[48] Berente, N., Vandenbosch, B., and Aubert, B. 2009. Information Flows and Business Process Integration. Business Process Management Journal, 15(1).

[49] Tambovcevs, A., and Merkuryev, Y. (2009). Analysis of ERP systems implementation in the construction enterprises", Scientific Journal of Riga Technical University, 39(1), 16-26

[50] Hawking, P. (2006). Implementing ERP systems globally: Challenges and lessons learned for Asian countries. Journal of Business Systems, Governance and Ethics, 2(1), 21-32.

[51] Plant, R., and Willcocks, L. 2007. "Critical success factors in international ERP implementations: A case research approach", Journal of Computer Information Systems, 1: 60-70.

[52] Kansal, V. (2006). The enterprise systems implementation: An integrative framework. The Review of Business Information Systems, 10(2), 21-27

[53] Dezdar, S., and Sulaiman, A. (2009). Successful enterprise resource planning implementation: taxonomy of critical factors. Industrial Management + Data Systems, 109(8), 1037-1052

[54] Kamhawi, E., M. (2008) "Determinants of Bahraini managers' acceptance of business process reengineering", Business Process Management Journal, Vol. 14 Iss: 2, pp. $166-187$.

[55] Seethamraju, R. (2008). Enterprise system's characteristics in small and medium-sized enterprises context - A case study. European and Mediterranean Conference on Information Systems.

[56] Rettig, C. (2007). The trouble with enterprise software. MIT Sloan Management Review 49(1), 21-27.

[57] Kemp, M. J., and Low, G. C. (2008). ERP innovation implementation model incorporating change 
management. Business Process Management Journal, $14(2), 228-242$

[58] Esteves, J. M., and Bohorquez, V. (2007). An updated ERP systems annotated bibliography: 2001-2005. Communications of the Association for Information Systems, 19, 386-446

[59] Xue, Y., Liang, H., Boulton, W. R., and Snyder, C. A. (2006). ERP implementation failures in China: Case studies with implications for ERP vendors. International Journal of Production Economic, 97, 279-295

[60] Law, C., Chen, C., and Wu, B. (2010). Managing the full ERP life-cycle: Considerations of maintenance and support requirements and IT governance practice as integral elements of the formula for successful ERP adoption. Computers in Industry, 61(3), 297-308

[61] Kumar, V., Maheshwari, B., and Kumar, U. (2008). An investigation of critical management issues in ERP implementation: Empirical evidence from Canadian organizations. Technovation, 23(2003), 793-807

[62] Ifinedo, P. (2007). An empirical study of ERP success evaluations by business and IT managers. Information Management and Computer Security, 15(4), 270-282

[63] Saatçioglu, O. O. (2009). What determines user satisfaction in ERP projects: benefits, barriers or risks? Journal of Enterprise Information Management, 22(6), 690-708

[64] Ghosal, V., and Nair-Reichert, U. (2009). Investments in modernization, innovation and gains in productivity: Evidence from firms in the global paper industry. Research Policy, 39(3), 563-547

[65] Velcu, O. (2010). Strategic alignment of ERP implementation stages: An empirical investigation. Information and Management, 47(3), 158-166

[66] Sammon, D., and Adam, F. (2010). Project preparedness and the emergence of implementation problems in ERP projects. Information and Management, 47(1): 1-8

[67] Cheung, W., Maropoulos, P., and Matthews, P. (2010). Linking design and manufacturing domains via webbased and enterprise integration technologies. International Journal of Computer Applications in Technology, 37(3/4):182-197

[68] Chen, C. C., Law, C. H., and Yang, S. C. (2009). Managing ERP implementation failure: A project management perspective. IEEE Transactions on Engineering Management, 56 (1), 157-170

[69] Maguire, S., Ojiako, U., and Said, A. (2010). ERP implementation in Omantel: A case study. Industrial Management + Data Systems, 110(1), 78-92

[70] Dey, P. K., Clegg, B. T., and Bennett. D. J. (2010). Managing enterprise resource planning projects Business Process Management Journal, 16(2), 282-296.

[71] Malhotra, R., and Temponi, C. (2010). Critical decisions for ERP integration: Small business issues. International Journal of Information Management, 30(1), 28-37

[72] Huang, S-H., Huang, S-M., Wu, T-W., and Lin, T-H. (2009). Process efficiency of the enterprise resource planning adoption. Industrial Management + Data Systems, 109(8), 1085-1100

[73] Chen, K., Razi, M., and Tarn, J. (2009). Empirical assessment of ERP learning effects. Human Systems Management, 28(4), 183-192

[74] Capaldo, G., and Rippa, P. (2009). A planned-oriented approach for EPR implementation strategy selection. Journal of Enterprise Information Management, 22(6): $642-659$

[75] Ge, L., and Voss, S. (2009). ERP application in China: An overview. International Journal of Production Economics, 122(1), 501

[76] Kouki, R., Poulin, D., and Pellerin, R. (2010). The impact of contextual factors on ERP assimilation: Exploratory findings from a developed and a developing Country. Journal of Global Information Technology Management, 13(1), 28-55

[77] Al-Mashari, M., and Al-Mudimigh, A. (2003). ERP Implementation: Lessons from a Case Study. Information Technology and People, 16(1), 21-32

[78] Laudon, K., and Laudon, P. (2006). Management Information Systems: Managing the Digital Film, (9th Ed). Prentice Hall

[79] O'Brien, J. (1997). Management Information Systems: A Managerial End User Perspective (3rd Ed). McGraw Hill-Irwin Inc

[80] Coleman, P. (n.d). ERP implementation options RetrievedJanuary26,2011 from http://www.intermec.com 